\author{
Military Technical College \\ Kobry El-Kobbah, \\ Cairo, Egypt
}

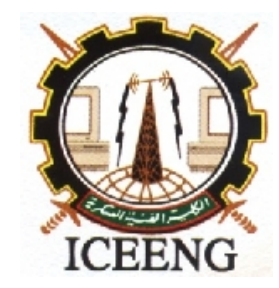

\section{$7^{\text {th }}$ International Conference on Electrical Engineering ICEENG 2010}

\title{
A Hybird Algorithm For Blocking Power Swings
}

\author{
By \\ Doaa Khalil Ibrahim * Ahmed Faheem Zobaa ** Essam Abo El-Zahab * Ghada M. Abo-Hamad
}

\begin{abstract}
$\underline{\text { Abstract: }}$
The effect of fast power swing conditions causes the apparent impedance 'seen' by distance protection schemes to vary over a wide range. This paper aims to moderate a directional impedance relay by adding a Wavelet Transform (WT) block and combines the outputs in a hybrid algorithm to detect a fault as well as fault during power swing, and blocks relay operation during power swings. The proposed relay has been tested for power swing conditions with different loading conditions and different power angles. In addition, testing the proposed scheme for fault conditions with different fault locations, different fault resistance, different fault types, and different inception angles had been carried out. The integrated relay had been tested on a simulated system using MatLab program.
\end{abstract}

\section{Keywords:}

Directional Relaying, Power Swings, Transmission lines, Wavelet Transform.

* Faculty of Engineering, Cairo University, Cairo, Egypt

** University of Exeter, United Kingdom. 


\section{Introduction:}

Distance protection relays are commonly used for the protection of transmission lines. Basic principles employ steady-state phasor approach [1]. The steady-state approach may involve well-known algorithms based on Discrete Fourier Transform [2], Kalman filtering [3], or symmetrical components.

These algorithms work on the estimation of fundamental frequency components of voltages and currents. These types of algorithms need about one cycle of signal to extract the fundamental frequency and may be much longer.

Also, any sudden change in the configuration or the loading of an electrical network causes a power swing between the load concentrations of the network [4]. The current flowing through the transmission line depends upon the phase difference between voltages generated at the two ends of the line. The phase difference is equal to the rotor angle. The phase angle between the generated voltages changes during disturbances which may arise because of the removal of a fault or a sudden change in the load. During disturbances, the rotor of the generator swings around the final steady state value. When the rotor swings, the rotor angle changes and the current flowing through the line also changes. Such currents are heavy and known as power swings [5]. So long as the phase angle between the generated voltages goes on changing. Therefore, the impedance measured by the relay appears like a fault also varies during power swings.

Thus, a power swing 'seen' by the relay appears like a fault which changes its distance from the relay location. The characteristic of directional impedance relay and power swings are shown on the R-X diagram of Fig. 1 [5].

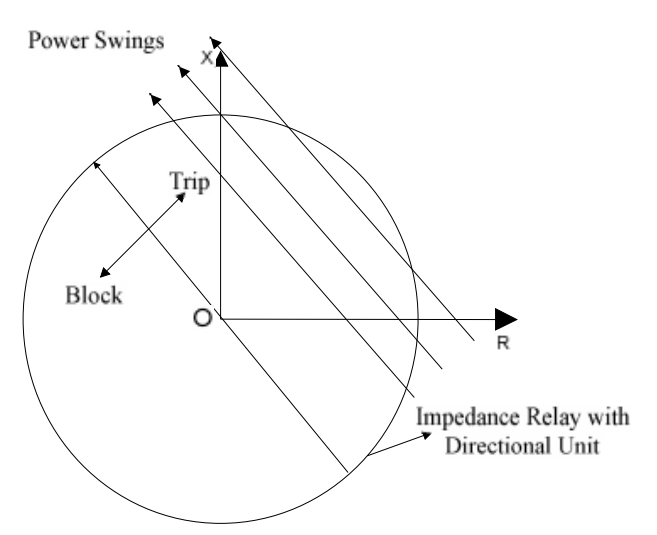

Figure(1): Effect of power swings on impedance relays.

During the last decade, several schemes for the discrimination of power swings and faults have been proposed. In [6], consider the changing frequency in their formulation; a time invariant (d-q) frame was built to track the load angle and differentiate between a swing and a fault, however, it considers only single-phase faults. In [7], a modification 
had been done for detecting a high resistance earth fault during a power swing for symmetrical faults, which are really most likely to be confused with a power swing. Phase selector during power swing is proposed in [8] by utilizing the Series Multiresolution Morphological Gradient (SMMG) transform to extract the superimposed components of modular currents. This scheme used only for unbalanced faults and the faulty phase can be identified within one-and-a-half cycles after fault inception during a power swing. A novel unblocking criterion based on the variation rates of both active and reactive power to identify the symmetrical faults occurring during power swings is proposed in [9]. This method fails in case of unsymmetrical faults.

Wavelet Transform (WT) had been extensively used in power system analysis in recent years. In [10], the use of Wavelet Transform is introduced to detect a power swing and to detect any fault during a power swing. The ninth current signal detail captures the current variations around the nominal frequency and hence can be used to detect a power swing. The summation signals of the first four voltage details capture the energy of fault transients and hence can be used to detect inception of a fault during swing condition.

For the reason mentioned before ( impedance relay mal-operation in case of power swings), this paper proposes adding a WT logic block to moderate a directional impedance relay and combines the outputs in a hybrid algorithm to detect faults during power swing, and to prevent relay operation during power swings. Performance of the proposed relay has been tested for tens times and investigated extensively for power swing conditions with different loading conditions and different power angles. Furthermore, testing the proposed scheme for fault conditions with different fault locations, different fault resistance, different fault types, and different inception angles had been carried out.

\section{$\underline{\text { 2. Key Issues To Consider }}$}

The proposed hybrid relaying scheme consists of two algorithms operating in parallel operation: a relay based on wavelet transform information (WT relay) and a relay based on impedance measurement (directional impedance relay). Extraction of wavelet information and calculation of impedance are carried out simultaneously. Both relays use the same voltage signals. The WT relay relies on capturing high frequency transient signals, and hence the $50 \mathrm{~Hz}$ component has to be removed from the measured waveforms. On the other hand, the Directional Impedance Relay uses the fundamental frequency components and high frequency noise has to be filtered out.

The voltages and current signals must be sampled at a sampling rate of $(50 \mathrm{kHz})$. The outputs of the two algorithms have to be combined effectively to utilize the positive features of both algorithms, thereby optimizing both speed and reliability. 


\section{Hybrid Relaying Scheme}

A scheme based on using two relays one at each end of the line is proposed in this paper. Fig. 2 shows the studied transmission line model. All the three current signals and three voltage signals on each end are needed for the proposed scheme. By using wavelet transform (WT), it is easy to detect any disturbance or faults on the lines and Fourier transform (FFT) is used to estimate the phasors of the measured signals [11]. The proposed scheme is based on the fast fault/power swing detection and phasor estimation to block the mal-operation of relay tripping during rapid power swings.

\section{A- Directional Impedance Relay}

The line impedance is calculated from the fundamental frequency component of the voltage and current signals. The $50 \mathrm{~Hz}$ values are extracted using full cycle Fast Fourier Transform (FFT). The ground and phase relays calculate the phase to ground and phase to phase impedances parallelism. When the calculated impedance falls within the protection zone, a fault is indicated. The equations that govern the relationship between voltages and currents are different for each fault and listed in Table 1. But directional impedance relay may fail to detect a fault during power swing or may operate during power swing. Typical waveforms during power swing are shown in Fig. 3.

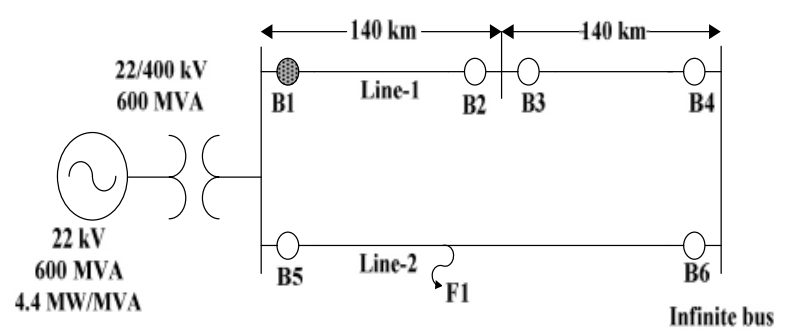

Figure(2): Parallel transmission line model

Table(1): Apparent impedance calculation equations

\begin{tabular}{||c|c|c||}
\hline Relay Element & Fault Type & Equation \\
\hline \hline \multirow{3}{*}{ Ground Relay } & $\mathrm{A}-\mathrm{G}$ & $\mathrm{VA} /(\mathrm{IA}+3 \mathrm{~m} \varphi . K . I o)$ \\
\cline { 2 - 3 } & $\mathrm{B}-\mathrm{G}$ & $\mathrm{VB} /(\mathrm{IB}+3 \mathrm{~m} \varphi . K . I o)$ \\
\cline { 2 - 3 } & $\mathrm{C}-\mathrm{G}$ & $\mathrm{VC} /(\mathrm{IC}+3 \mathrm{~m} \varphi . K . \mathrm{Io})$ \\
\hline \multirow{3}{*}{ Phase Relay } & $\mathrm{A}-\mathrm{B}$ & $(\mathrm{VA}-\mathrm{VB}) /(\mathrm{IA}-\mathrm{IB})$ \\
\cline { 2 - 3 } & $\mathrm{B}-\mathrm{C}$ & $(\mathrm{VB}-\mathrm{VC}) /(\mathrm{IB}-\mathrm{IC})$ \\
\cline { 2 - 3 } & $\mathrm{C}-\mathrm{A}$ & $(\mathrm{VC}-\mathrm{VA}) /(\mathrm{IC}-\mathrm{IA})$ \\
\hline
\end{tabular}

Where: $\mathrm{A}, \mathrm{B}$, and $\mathrm{C}$ denote phase quantities. Letter $\mathrm{G}$ denotes ground faults. $\mathrm{m} \varphi=\mathrm{I} \varphi / \mathrm{Imax}$, is the compensation factor. $\mathrm{K}=\left(\mathrm{Z}_{\mathrm{o}}-\mathrm{Z}_{1}\right) / \mathrm{Z}_{1}$ and $\mathrm{I}_{\mathrm{o}}$ is the zero sequence 
current. $Z_{o}$ and $Z_{1}$ are the zero and positive sequence line impedance.

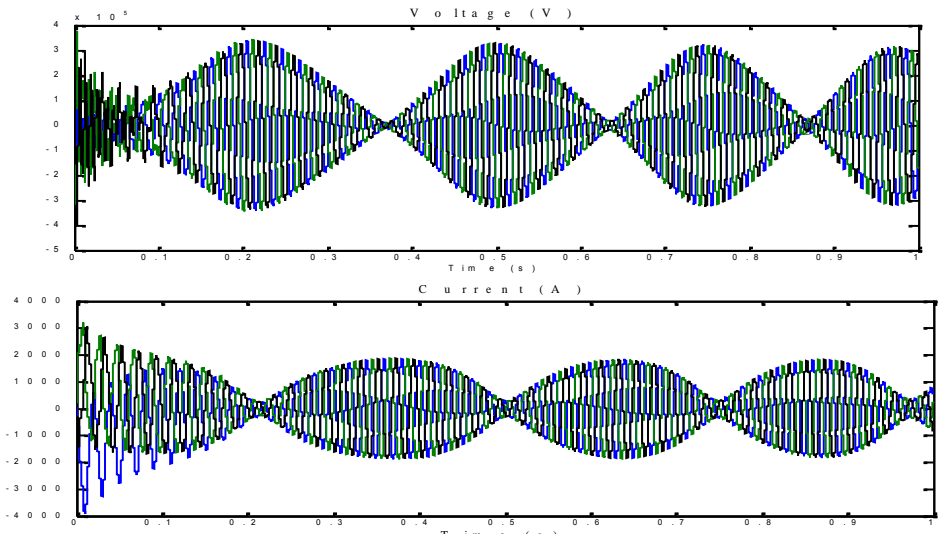

Figure(3): Typical voltage and current waveforms during a power swing.

\section{B-Wavelet Transform Relay}

In the proposed wavelet algorithm, fault detection can be obtained from the details of the first decomposition level of the measured voltage signals using symlets 3 wavelet. This level contains the high frequencies that are associated with faults [11]. The length of the sliding data window used for fault detection is equal to half cycle of the fundamental frequency. By calculating the norm value of the first detail coefficient (D1) for all voltages; therefore, the phase(s) on disturbances can be identified. If the calculated norm value of any phase exceeds a certain threshold, this indicates that this phase is exposed to a disturbance. The value of the threshold is chosen based on extensive simulations of the studied system, which depends on the power system circumstances. The calculated norm of D1 measures the amount of energy content in over a half cycle D1 as follows:

$D=\sqrt{\frac{\sum_{i=1}^{M} d^{2}(i)}{M}}$

Where: $\mathrm{M}=$ the number of samples in half cycle.

$\mathrm{d}(\mathrm{i})=$ detail coefficient of sample $\mathrm{i}$ at first detail.

\section{C-Hybrid Detection Algorithm}

A block diagram of the proposed detection algorithm is shown in Fig. 4. Three voltage and current signals are feed into directional impedance relay, but only three voltages signals are feed into a WT relay. The hybrid algorithm can discriminate effectively between tripping for faults with and without power swings and blocking for power swings as follows: 


\section{If there is a fault in the protected line:}

The measured impedance from directional impedance relay falls within the protected zones, this relay sends a signal to remote end relay and the remote end relay also sends a signal to terminal relay, therefore directional impedance relay indicates a fault. If norm D1 exceeds threshold, WT relay indicates a fault. As a result, when the two relays indicate a fault, it ensures that a fault within the protected transmission line, a trip command will be achieved.

\section{If there is a power swing case:}

In such case, the directional impedance relay will operate alone but WT doesn't operate and therefore, trip issue will be blocked.

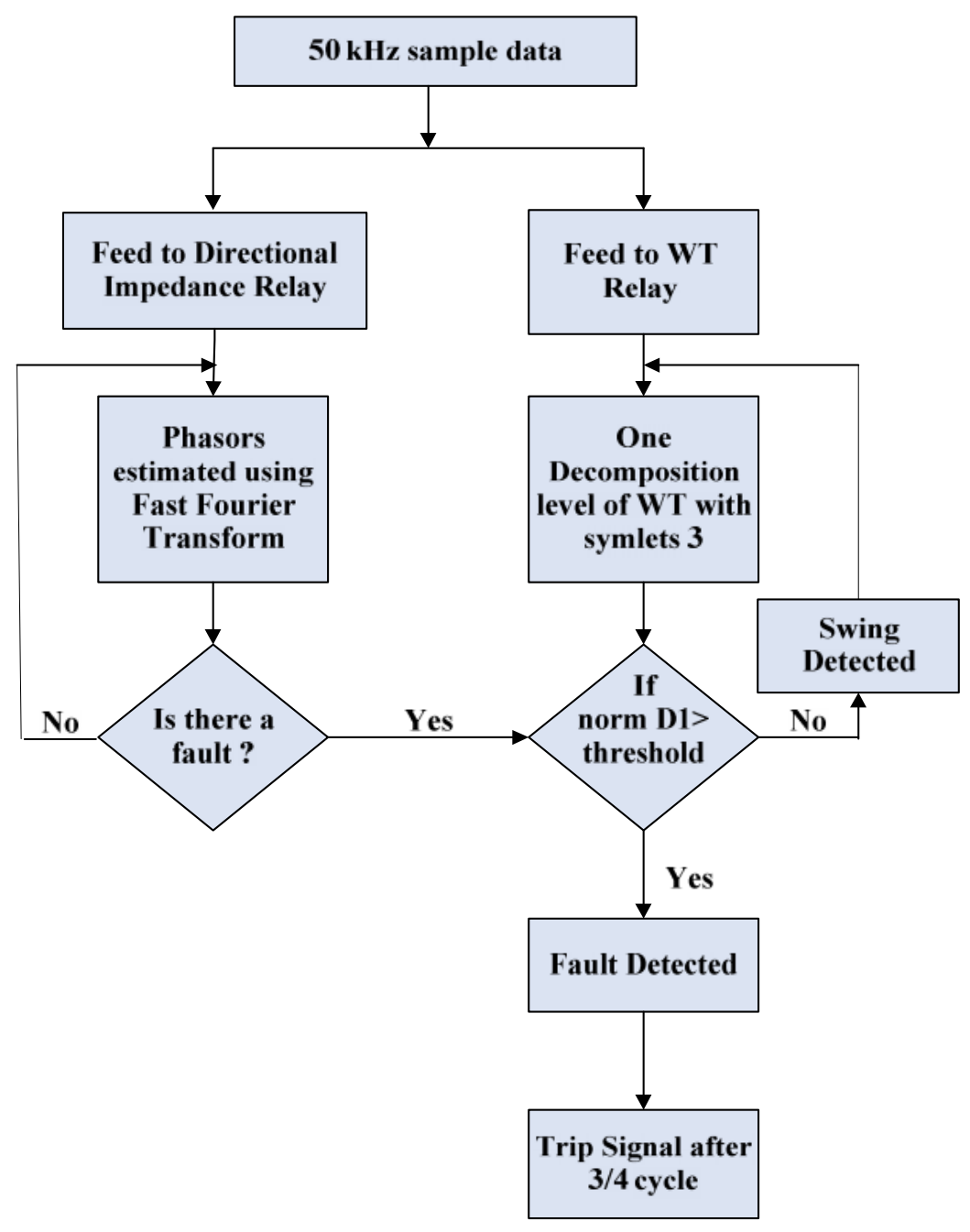

Figure(4): Flowchart of the proposed scheme. 


\section{Simulation Results}

In order to investigate the performance of the hybrid relaying scheme, a sample network has been simulated using MatLab program. The simulated power network is shown in Fig. 2. The network consists of two areas. The sending end (SE) which modeled as an equivalent machine and the receiving end (RE) that modeled as an infinite bus. In normal conditions, power is transferred from SE to RE via two parallel lines. Line-1 has two sections, each of $140 \mathrm{~km}$ length, and line- 2 is $280 \mathrm{~km}$ long. Lines are modeled with distributed parameters. The system details are given in the Appendix A.

The directional impedance relay at breaker B1 is considered as the studied relay in this study. Zone-1 of this relay covers $126 \mathrm{~km}$ which corresponds to an apparent impedance of 112 . The three typical scenarios had been investigated are:

- Power swings in line-1 had been simulated by a fault (F1 as shown in Fig.2) occurring at $0.1 \mathrm{~s}$ and cleared after $0.1 \mathrm{~s}$ by the opening of breakers B5 and B6 under different loading conditions. This sends the system into a power swing [12].

- Power swing in line-1 had been simulated by changing the power angle of main generator relative to the other end [4].

- Different fault conditions on line-1 with faults occur at $2 \mathrm{~s}$ during power swing conditions.

Due to the limitation of the length of this paper, only some cases of these scenarios are illustrated as examples in details in the following subsequent sections.

\section{A. Influence of the Power Angle}

The proposed relay has been tested for blocking during power swings simulated by changing power angles conditions. All cases studied had been tested for a fixed loading condition of 500 MVA. Some results had been presented in Figures 5, 6 for $\delta=120^{\circ}$ and $260^{\circ}$ respectively. Obviously, it can be seen that modeling the power angle changing between two ends of the transmission lines causes power swings in the transmission line, which may be rapid to cause undesirable operation of the distance relay (mal operation), but the hybrid relay operates correctly.

\section{B. Influence of the Heavy Loading}

Two cases are introduced in this paper for a three phase fault occurs during heavy loading. The voltage, current waveforms as seen by the relay B1, and the behavior of the three relays are shown in Figures 7,8 respectively. These cases can cause undesirable operations in case of using only conventional distance relay that results in undesirable trip signals. However by adding WT logic block, a blocking for tripping issue is achieved. 


\section{Discrimination between Faulty and Transient Events}

In the development of any fault-detection technique, it is important to ensure that it can discriminate effectively between normal non-fault events such as line switching and switching during fault events. The proposed hybrid relay presented here was extensively tested under many of such events.

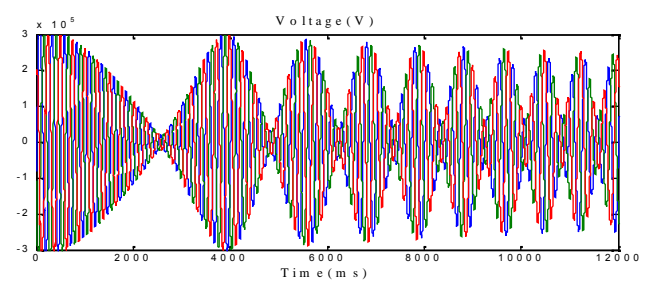

(a) Voltage waveforms

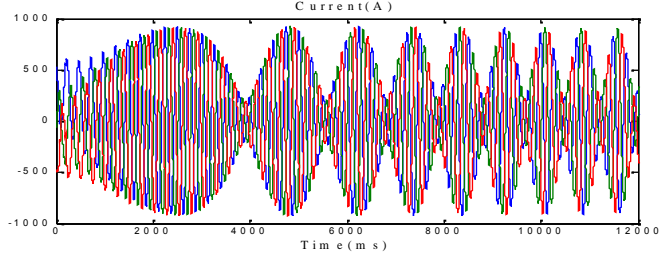

(b) Current waveforms

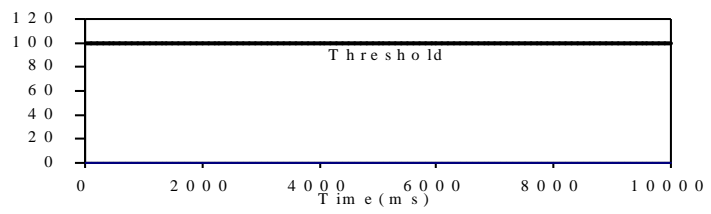

(c) Wavelet relay

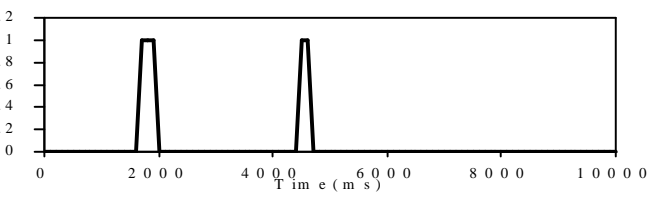

(d) Directional impedance relay

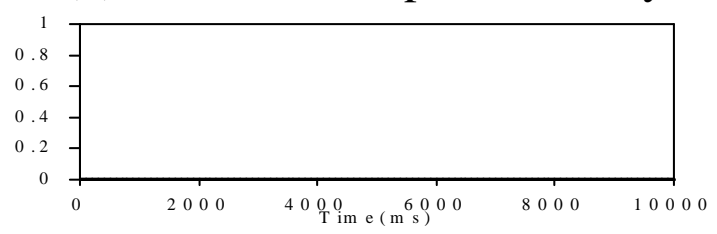

(c) Hybrid relay

Figure(5): Voltage, current, and relays performance for $\delta=120^{\circ}$

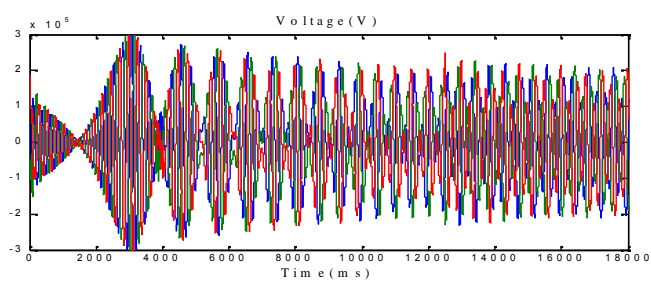

(a) Voltage waveforms

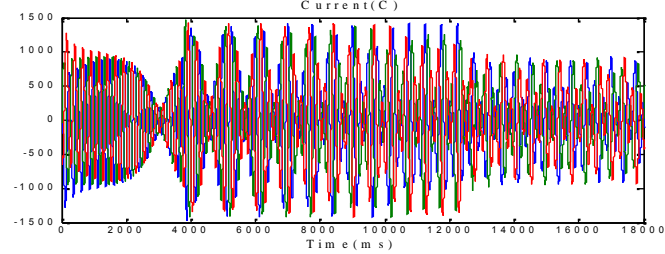

(b) Current waveforms

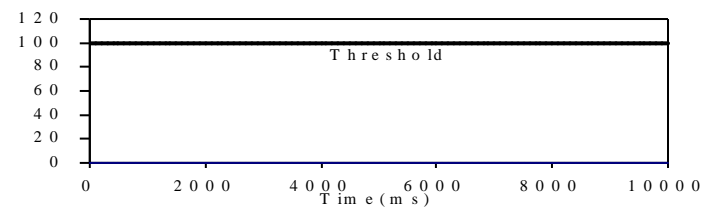

(c) Wavelet relay

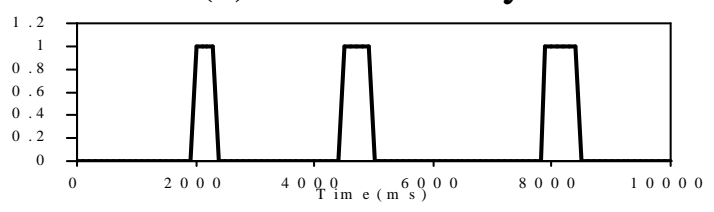

(d) Directional impedance relay

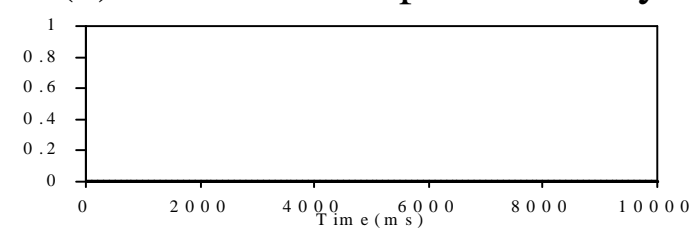

(c) Hybrid relay

Figure(6): Voltage, current, and relays performance for $\delta=260^{\circ}$

- In all normal switching cases, conventional directional relay responds very well; therefore, the proposed scheme ensures blocking mal operations in such cases.

- For switching during fault events, conventional directional relay responds very well; therefore, the proposed scheme ensures tripping in such cases. 
In addition, several fault conditions were carried out for the evaluation of the algorithm effectiveness by changing fault distance, resistance, and inception angles as well as fault types. In all tested cases, the performance of the proposed scheme is excellent for tripping faults.

As an example for the performance of the proposed scheme for activating tripping for faults during power swings, Fig. 9 shows the voltage, current, and performance of relays for phase-to-ground fault at $2 \mathrm{~s}$ during power swing. As obviously shown, power swing blocking is cleared at the instant of fault occurrence in transmission lines to ensure necessary tripping by the proposed scheme.

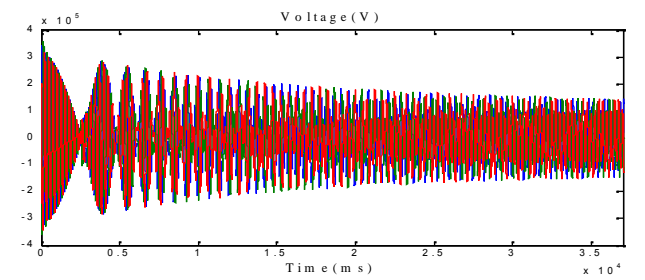

(a) Voltage waveforms

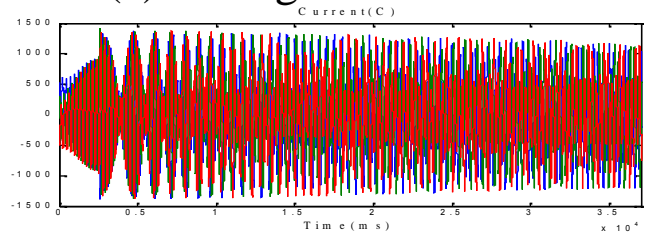

(b) Current waveforms

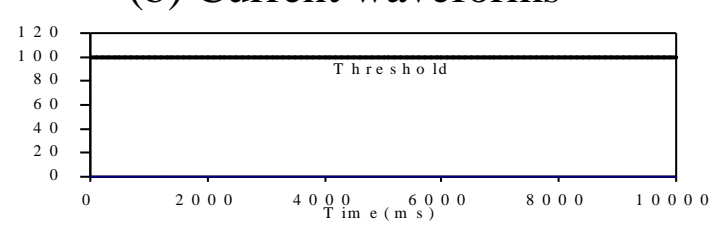

(c) Wavelet relay

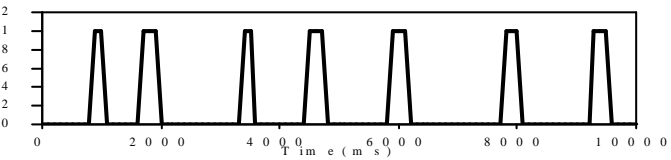

(d) Directional impedance relay

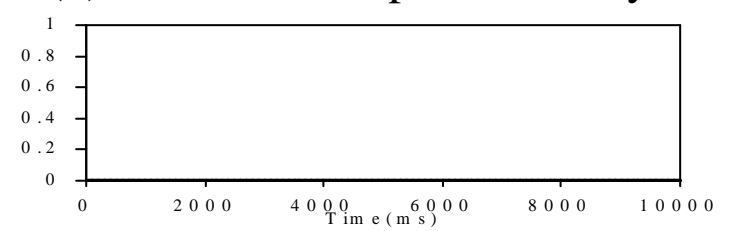

(c) Hybrid relay

Figure (7):Voltage, current, and relays performance for three-phase fault occurs under heavy loading (600MVA).

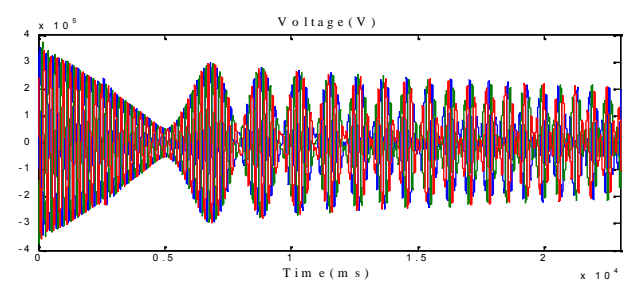

(a) Voltage waveforms

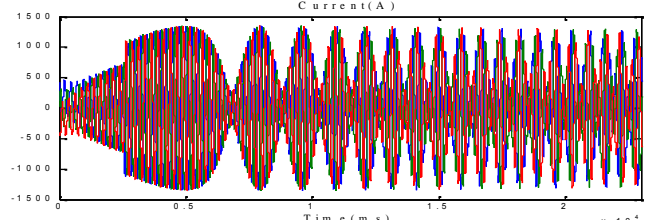

(b) Current waveforms

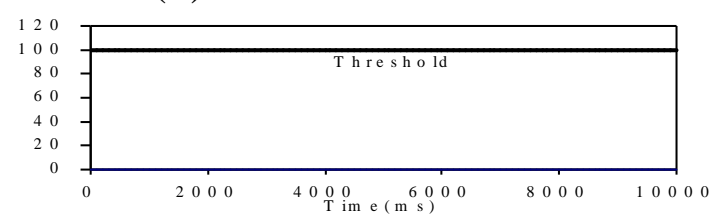

(c) Wavelet relay

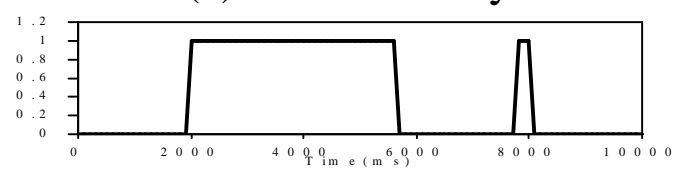

(d) Directional impedance relay

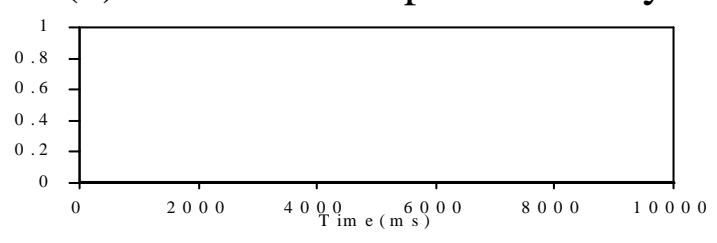

(c) Hybrid relay

Figure(8): Voltage, current, and relays performance for three-phase fault occurs under heavy loading (1000MVA). 


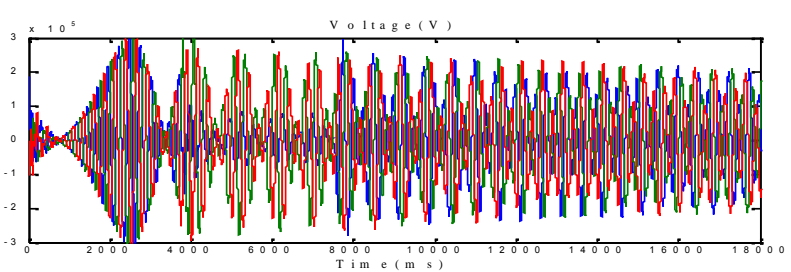

(a) Voltage waveforms

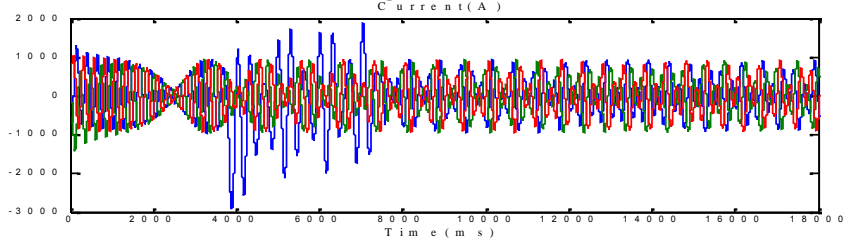

(b) Current waveforms

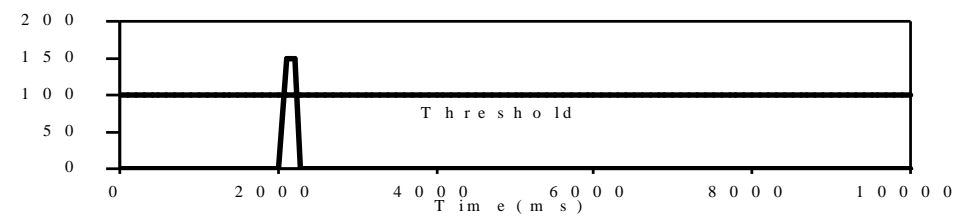

(c) Wavelet relay

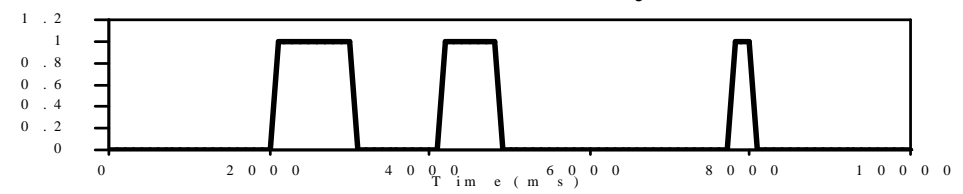

(d) Directional impedance relay

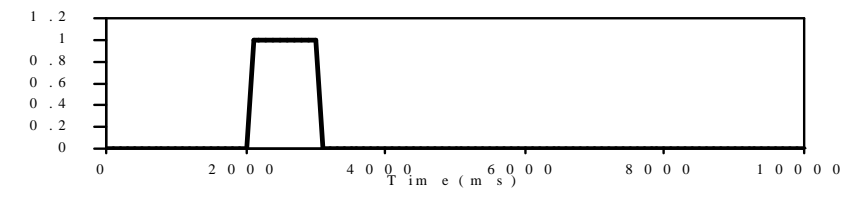

(c) Hybrid relay

Figure(9): Voltage, current, and the performance of relays for phase-to-ground fault at 2 s under power swing.

\section{Conclusions:}

A hybrid relay principle for blocking trip during fast power swings has been proposed that provides fault clearance once power swing blocking has been initiated. This principle is based on adding WT logic block to the directional impedance relay using the details of the first decomposition level of the measured voltage signals using symlets3 wavelet. With the proposed scheme, it is possible to clear power swing blocking at the instant a fault occurs in transmission lines.

To evaluate the performance of the proposed scheme, most of disturbances types have 
been modeled. Power swings conditions (under different loading conditions and power angles).

- Fault conditions (under different fault distances, fault inception angles, different fault types, and different fault resistances).

- Faults during Power Swings.

- Switching conditions without Faults.

- Switching conditions with Faults.

The proposed scheme can achieve faster fault detection speeds when compared to a standard distance relay, which is able to detect faults after $3 / 4$ cycle $(0.015 \mathrm{~s})$.

\section{References:}

[1] A. H. Osman, Tamer Abdelazim, and O. P. Malik, "Transmission Line Distance Relaying Using On-Line Trained Neural Networks.", IEEE Trans. Power Delivery, Vol. 20, No. 2, pp. 1257-1264, April 2005.

[2] Jyh-Cherng Gu, and Sun-Li Yu, " Removal of DC Offset in Current and Voltage Signals Using a Novel Fourier Filter Algorithm .", IEEE Trans. Power Delivery, Vol. 15, No. 1, pp. 73-79, January 2000.

[3] A. Girgis and E. B. Makram, "Application of Adaptive Kalman Filtering in Fault Classification, Distance Protection, and Fault Location Using Microprocessors.", IEEE Trans. Power Delivery, Vol. 3, No. 1, pp. 301-309, January 1988.

[4] Xiangning Lin, Yan Gao, and Pei Lin, "A Novel Scheme to Identify Symmetrical Faults Occurring during Power Swings." IEEE Trans. Power Delivery, Vol. 23, No. 1, pp. 73-78, January 2008.

[5] Badri Ram and DN Vishwakarma, "Power System Protection and Switchgear." McGraw-Hill Publishing Company Limited.

[6] A. Mechraoui, A., D.W.P. Thomas, " A New Blocking Principle With Phase and Earth Fault Detection during Fast Power Swing Blocking Schemes for Distance Protection." IEEE Trans. Power Delivery, Vol.10, No. 3, pp. 1242-1248, July 1995.

[7] A. Mechraoui, A., D.W.P. Thomas, "A New Principle for High Resistance Earth Fault Detection during Fast Power Swings for Distance Protection." IEEE Trans. Power Delivery, vol.12, no. 4, pp. 1452-1457, Oct. 1997.

[8] Li Zou, Qingchun Zhao, Xiangning Lin, and Pei Liu, "Improved Phase Selector for Unbalanced Faults during Power Swings Using Morphological Technique." IEEE Trans. Power Delivery, vol. 21, no. 4, pp. 1847-1855, Oct.2006.

[9] Chul-Hwan Kim, Hyun Kim, Young-Hun Ko, Sung-Hyun Byun, Raj K. Aggarwal, and Allan T. Johns, " A Noval Fault-Detection Technique of HighImpedance Arcing Faults in Transmission Lines Using the Wavelet Transform.", IEEE Trans. Power Delivery, Vol. 17, No. 4, pp. 921-929, Oct. 2002. 
[10] Sukumar M. Brahma, "Distance Relay with Out-of-Step Blocking Function Using wavelet Transform." IEEE Trans. Power Delivery, Vol. 22, No. 3, pp. 1360-1366, July 2007.

[11] A. H. Osman, and O. P. Malik, "Transmission Line Distance Protection Based on Wavelet Transform." IEEE Trans. Power Delivery, Vol. 19, No. 2, pp. 515-523, April 2004.

[12] S. A. Soman, Tony B. Nguyen, M. A. Pai, and Rajani Vaidyanathan, " Analysis of Angle Stability Problems: A Transmission Protection Systems Perspective." IEEE Transactions Power Delivery, Vol. 19, No. 3, July 2004, PP. 1024-1032.

\section{Appendix:}

The parameters of the system used for simulation (Fig. 3) are given below [10].

Equivalent Generator G: $600 \mathrm{MVA}, 22 \mathrm{kV}, 50 \mathrm{~Hz}$.

$\mathrm{Xd}=1.81$ p.u., $\mathrm{X}^{\prime} \mathrm{d}=0.3$ p.u., $\mathrm{X}^{\prime \prime} \mathrm{d}=0.23$ p.u., $\mathrm{T}^{\prime} \mathrm{do}=8 \mathrm{~s}, \mathrm{~T}^{\prime \prime} \mathrm{do}=0.03 \mathrm{~s}, \mathrm{Xq}=1.76$ p.u., $X " q=0.25$ p.u., $T " q o=0.03$ s, $R a=0.003$ p.u., $X p($ Potier reactance $)=0.15$ p.u.

Transformer: $600 \mathrm{MVA}, 22 / 400 \mathrm{KV}, 50 \mathrm{~Hz}, \Delta / \mathrm{Y}, \mathrm{X}=0.163$ p.u., Xcore $=0.33$ p.u., Rcore $=0$, Pcopper $=0.00177$ p.u.

Transmission lines data:

$\mathrm{Z} 1=0.12+\mathrm{j} 0.88 \quad / \mathrm{km}, \mathrm{Zo}=0.309+\mathrm{j} 1.297 \quad / \mathrm{km}, \mathrm{C} 1=1.0876 \times 10-8 \mathrm{~F} / \mathrm{km}$.

\section{Nomenclatures:}

$\delta \ldots$ Power angle

M ... The number of samples in half cycle Acceleration

d(i)... Detail coefficient of sample $i$ at first detail.

\section{$\underline{\text { Biographies }}$}

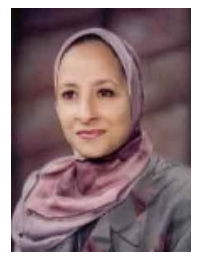

Doaa khalil Ibrahim (IEEE M'06) was born in Egypt in Dec. 1973. She graduated from Cairo University, Faculty of Engineering, Electrical Power and Machines Department in 1996 and received the M.Sc. and Ph.D. in digital protection from Cairo University at 2001 and 2005, respectively. From 1996 till 2005 she was a demonstrator and research assistant in Cairo University. In September 2005, she became an assistant professor with Cairo University. From October 2005 till Dec.2008, Dr. D. Khalil was contributing in a World Bank Project in Higher Education Development in Egypt. From January 2009, she contributes in the Program of Continuous Improvement and Qualification for Accreditation in Higher Education in Egypt. Her research interests include digital protection of power system, utilization and generation of electric power and renewable energy sources. 


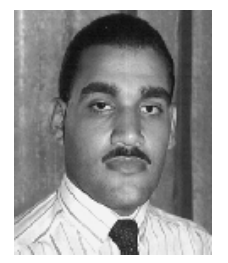

Ahmed Faheem Zobaa (IEEE M'01-IEEE SM'04) received the B.Sc., M.Sc., and Ph.D. degrees in electrical power and machines from Faculty of Engineering at Cairo University, Giza, Egypt, in 1992, 1997, and 2002, respectively. Currently, he is an Assistant Professor in the Department of Electrical Power and Machines with the Faculty of Engineering, Cairo University. He was an Instructor in the Department of Electrical Power and Machines with the Faculty of Engineering at Cairo University from 1992 to 1997, and Teaching Assistant from 1997 to 2002. From 2008, He becomes a Senior Lecturer in Renewable Energy (Electrical Engineering), School of Engineering, Mathematics \& Physical Sciences, University of Exeter, UK. His areas of research include harmonics, compensation of reactive power, power quality, photovoltaics, wind energy, education, and distance learning. He is an Editorial Board member for Electric Power Components and Systems Journal and International Journal of Computational Intelligence. He is an Editor of IEEE Power Engineering Letters. Also, he is an Associate Editor for the IEEE Transactions on Industrial Electronics, International Journal of Power and Energy Systems, and International Journal on Modeling and Simulation.

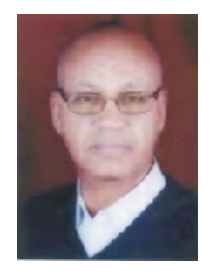

Essam EL-Din Abou EL-Zahab Received the BSc. and MSc. degrees in electrical power and machines from Cairo University, Giza, Egypt, in 1970 and 1974, respectively. He received the $\mathrm{PhD}$. degree in Electrical Power from Paul Sabatier, France, in 1979. Currently he is a Professor in the department of electrical power and machines at Cairo University. He was an instructor in the department of electrical power and machines at Cairo University from 1970 to 1974. His research areas include protection system, renewable energy, and power distribution. He is also the author or co-author of many referenced journal and conference papers.

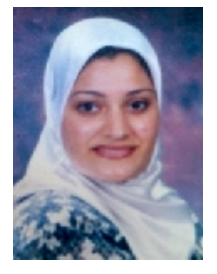

Ghada M. Abo-Hamad received the B.Sc. degree in electrical power and machines from Cairo University, Giza, Egypt, in 2002. She received the M.Sc. in digital protection in electrical engineering, from Cairo University at 2009. 